\title{
CO hydrogenation combined with water-gas-shift reaction for synthetic natural gas production: a thermodynamic and experimental study
}

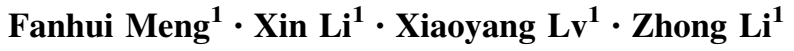

Received: 9 March 2017/Revised: 19 April 2017/Accepted: 11 July 2017 / Published online: 28 July 2017

(C) The Author(s) 2017. This article is an open access publication

\begin{abstract}
The hydrogenation of $\mathrm{CO}$ to synthetic natural gas (SNG) needs a high molar ratio of $\mathrm{H}_{2} / \mathrm{CO}$ (usually large than 3.0 in industry), which consumes a large abundant of hydrogen. The reverse dry reforming reaction (RDR, $2 \mathrm{H}_{2}$ $+2 \mathrm{CO} \leftrightarrow \mathrm{CH}_{4}+\mathrm{CO}_{2}$ ), combining $\mathrm{CO}$ methanation with water-gas-shift reaction, can significantly decrease the $\mathrm{H}_{2} / \mathrm{CO}$ molar ratio to 1 for SNG production. A detailed thermodynamic analysis of RDR reaction was carried out based on the Gibbs free energy minimization method. The effect of temperature, pressure, $\mathrm{H}_{2} / \mathrm{CO}$ ratio and the addition of $\mathrm{H}_{2} \mathrm{O}, \mathrm{CH}_{4}$, $\mathrm{CO}_{2}, \mathrm{O}_{2}$ and $\mathrm{C}_{2} \mathrm{H}_{4}$ into the feed gas on $\mathrm{CO}$ conversion, $\mathrm{CH}_{4}$ and $\mathrm{CO}_{2}$ selectivity, as well as $\mathrm{CH}_{4}$ and carbon yield, are discussed. Experimental results obtained on homemade impregnated $\mathrm{Ni} / \mathrm{Al}_{2} \mathrm{O}_{3}$ catalyst are compared with the calculations. The results demonstrate that low temperature $\left(200-500{ }^{\circ} \mathrm{C}\right.$ ), high pressure $\left(1-5 \mathrm{MPa}\right.$ ) and high $\mathrm{H}_{2} / \mathrm{CO}$ ratio (at least 1$)$ promote $\mathrm{CO}$ conversion and $\mathrm{CH}_{4}$ selectivity and decrease carbon yield. Steam and $\mathrm{CO}_{2}$ in the feed gas decrease the $\mathrm{CH}_{4}$ selectivity and carbon yield, and enhance the $\mathrm{CO}_{2}$ content. Extra $\mathrm{CH}_{4}$ elevates the $\mathrm{CH}_{4}$ content in the products, but leads to more carbon formation at high temperatures. $\mathrm{O}_{2}$ significantly decreases the $\mathrm{CH}_{4}$ selectivity and $\mathrm{C}_{2} \mathrm{H}_{4}$ results in the generation of carbon.
\end{abstract}

Keywords Synthetic natural gas - Reverse dry reforming of methane - Gibbs free energy minimization - Experimental study $\cdot$ CO conversion

\section{List of symbols}

$\mathrm{A}_{k} \quad$ Total mass of $k$ element in the feed

$f_{i}^{\Theta} \quad$ Standard-state fugacity of species $i(\mathrm{~Pa})$

$f_{i} \quad$ Fugacity of species $i(\mathrm{~Pa})$

$G_{i} \quad$ Gibbs free energy of species $i(\mathrm{~J} / \mathrm{mol})$

$\mathrm{G}_{i}^{\Theta} \quad$ Standard Gibbs free energy of species $i(\mathrm{~J} / \mathrm{mol})$

$\Delta \mathrm{G}_{f i}^{\Theta} \quad$ Standard-state Gibbs free energy of formation of species $i(\mathrm{~J} / \mathrm{mol})$

$G_{\mathrm{C}(\mathrm{g})}$ Partial molar Gibbs free energy of gas carbon $(\mathrm{J} / \mathrm{mol})$

$G_{\mathrm{C}(\mathrm{s})} \quad$ Partial molar Gibbs free energy of solid carbon $(\mathrm{J} / \mathrm{mol})$

Zhong Li

lizhong@tyut.edu.cn

1 Key Laboratory of Coal Science and Technology of Ministry of Education and Shanxi Province, Institute of Coal Chemical Engineering, Taiyuan University of Technology, No. 79 West Yingze Street, Taiyuan 030024, Shanxi, China
$G_{f \mathrm{C}(\mathrm{s})}^{\Theta} \quad$ Standard-state Gibbs function of formation of solid carbon $(\mathrm{J} / \mathrm{mol})$

$\triangle_{\mathrm{r}} H_{\mathrm{m}}^{\Theta} \quad$ Standard-state reaction enthalpy change $(\mathrm{J} / \mathrm{mol})$

$K^{\Theta} \quad$ Standard-state equilibrium constant

$n_{i} \quad$ Mole of species $I(\mathrm{~mol})$

$n_{\mathrm{C}} \quad$ Mole of carbon (mol)

$N \quad$ Number of components

$P \quad$ System pressure $(\mathrm{Pa})$

$p^{\Theta} \quad$ Pressure of the standard state $(\mathrm{Pa})$

$R \quad$ Molar gas constant $(\mathrm{J} /(\mathrm{mol} \mathrm{K})$

$T \quad$ Temperature (K)

$y_{i} \quad$ Mole fraction of species $i$

\section{Greek symbols}

$\alpha_{i k} \quad$ Number of atoms of the $k$ element present in each molecule of species $i$

$\mu_{i} \quad$ Chemical potential of species $i(\mathrm{~J} / \mathrm{mol})$

$\phi_{i} \quad$ Fugacity coefficient of species $i$

$\lambda_{k} \quad$ Lagrange multiplier 


\section{Introduction}

Natural gas is a highly efficient and clean fossil fuel due to its high calorific value, low sooting tendency and slag free products, leading to its increasing consumption year by year (Gao et al. 2015; Meng et al. 2015a; Rönsch et al. 2016). In 2014, the consumption of natural gas in China increased to 197.3 billion cubic meters, with a growth rate of $30.9 \%$ every year in the last decade (BP 2016). Recently, the consumption of natural gas has raised a serious concern regarding its depletion because of its limited reserves (Kopyscinski et al. 2010; Huo et al. 2013), in comparison, coal is considered as a much more abundant energy resource in many countries. The production of synthetic natural gas (SNG) from coal has been developed to be a potential route to circumvent the limited supply of natural gas, especially in China ( $\mathrm{Li}$ et al. 2014a, b; Lu et al. 2014).

Among the coal-to-SNG production processes, SNG is produced through the four major steps, i.e., coal gasification, water-gas-shift (WGS) reaction $\left(\mathrm{CO}+\mathrm{H}_{2} \mathrm{O} \leftrightarrow \mathrm{H}_{2}+\right.$ $\left.\mathrm{CO}_{2}\right)$, gas cleaning and $\mathrm{CO}$ methanation $\left(3 \mathrm{H}_{2}+\mathrm{CO} \leftrightarrow\right.$ $\mathrm{CH}_{4}+\mathrm{H}_{2} \mathrm{O}$ ) (Shinde and Madras 2014; Wang et al. 2015). The CO methanation reaction is a key process for increasing SNG production (Meng et al. 2015b; Götz et al. 2016; Gao et al. 2016). If one mole of CO is converted to methane, three moles of $\mathrm{H}_{2}$ are stoichiometrically required. However, the content of carbon in coal is usually more than $60 \mathrm{wt} \%$ (up to more than $90 \mathrm{wt} \%$ in bituminous coal) whereas that of hydrogen is $<5 \mathrm{wt} \%$ (Martelli et al. 2011; Shen et al. 2016). The high content of carbon in coal results in low $\mathrm{H}_{2} / \mathrm{CO}$ molar ratios, usually less than one, of produced gas from coal gasification (Messerle et al. 2016). For example, the produced gas of the British Gas-Lurgi (BGL) coal gasification process is composed of $60 \%-70 \% \mathrm{CO}$, $27 \%-30 \% \mathrm{H}_{2}, 0 \%-7 \% \mathrm{CH}_{4}, 1 \%-4 \% \mathrm{CO}_{2}$, and trace amounts of $\mathrm{O}_{2}$ and light hydrocarbons ( $\mathrm{Yu}$ and Wang 2010). To increase the $\mathrm{H}_{2} / \mathrm{CO}$ ratio, the WGS reaction should be well controlled. It is worthwhile to mention, in order to enhance the $\mathrm{CO}$ conversion and $\mathrm{CH}_{4}$ yield during industry processes, an even higher $\mathrm{H}_{2} / \mathrm{CO}$ ratio is usually used. For instance, the $\mathrm{H}_{2} / \mathrm{CO}$ ratio of the Lurgi process for methanation was optimized at about 3.2, and that of the Topsøe Recycle Energy Efficient Methanation (TREMP) process reached about 3.5 (Kopyscinski et al. 2010). More amount of $\mathrm{CO}$ needs to be converted to produce $\mathrm{H}_{2}$ by WGS reaction in order to get a high $\mathrm{H}_{2} / \mathrm{CO}$ ratio, which results in the high operating cost and energy consumption.

The reverse dry reforming (RDR) reaction $(2 \mathrm{CO}+$ $2 \mathrm{H}_{2} \leftrightarrow \mathrm{CH}_{4}+\mathrm{CO}_{2}$ ), which is the combination of $\mathrm{CO}$ methanation with WGS reaction, can be used to produce SNG. Recently, many studies have focused on the RDR reaction with the $\mathrm{H}_{2} / \mathrm{CO}$ ratio of one. Yan et al. (2013) found that the catalyst preparation methodologies significantly affected the activity and stability of $\mathrm{Ni} / \mathrm{SiO}_{2}$ catalysts. Jiang et al. $(2013,2014)$ investigated the stepwise sulfidation and sulfidation temperature on the catalytic activity of $\mathrm{MoO}_{3} / \mathrm{CeO}_{2}-\mathrm{Al}_{2} \mathrm{O}_{3}$. It is because there are many advantages of this reaction. First, the feed gas has a low $\mathrm{H}_{2} /$ $\mathrm{CO}$ ratio of one, which needs less hydrogen; Secondly, the water-free products can diminish the damage of steam on methanation catalyst, and the by-product $\mathrm{CO}_{2}$ can be easily removed by employing low-temperature methanol purification process. In other words, less $\mathrm{H}_{2}$ is needed from the gas of coal gasification, which simplifies the SNG production process and reduces the cost.

In literatures, data are available for the thermodynamic analysis of methanation reactions. Miguel et al. (2015) and Sahebdelfar et al. (2015) conducted a thermodynamic calculation of $\mathrm{CO}_{2}$ methanation based on the method of Gibbs free energy minimization and compared with the experimental data. Gao et al. (2012) analyzed the thermodynamic properties of several reactions during the complete methanation of $\mathrm{CO}$ and $\mathrm{CO}_{2}$. However, these thermodynamic studies were carried out based on the complete methanation reactions. To our knowledge, there is little information on the thermodynamic analysis of the RDR reaction that occurs at low temperatures. Therefore, it needs to perform the calculations based on the Gibbs free energy minimization method and validate the data through experimental means.

It is well known that the produced gas from coal contains many impurities, such as steam, $\mathrm{CO}_{2}, \mathrm{CH}_{4}, \mathrm{O}_{2}$ and light hydrocarbons of $\mathrm{C}_{2} \mathrm{H}_{4}$ and $\mathrm{C}_{2} \mathrm{H}_{6}$. In order to increase the production of SNG and optimize the $\mathrm{H}_{2} / \mathrm{CO}$ ratio of the produced gas, effects of these substances on the catalytic performance of the RDR reaction have to be investigated. Moreover, the yield of solid carbon should be taken into account during the thermodynamic analysis.

The objective of this work is to elucidate, through a thermodynamic study supported by experimental data, the effects of temperature, pressure and the other factors affecting the RDR reaction, such as the $\mathrm{H}_{2} / \mathrm{CO}$ molar ratio and addition of $\mathrm{H}_{2} \mathrm{O}, \mathrm{CH}_{4}, \mathrm{CO}_{2}, \mathrm{O}_{2}$, and $\mathrm{C}_{2} \mathrm{H}_{4}$ in feed gas on the catalytic activity and selectivity and the yield. For this purpose, this study does not take into account of reaction kinetics, practical heat and mass transfer processes. It is expected to produce necessary thermochemical data to describe the effectiveness of the RDR reaction and to provide useful guidance to chemical engineers for optimizing the individual processes.

\section{Methods}

\subsection{Thermodynamic analysis software}

The HSC Chemistry software 6.0 allows simulating chemical reactions and processing on the thermochemical data 
basis. In this study, the modules of reaction equations and equilibrium compositions were utilized to calculate the effects of various substances in conversion, selectivity and yield. The calculations were performed based on an extensive thermochemical database, which contains enthalpy $(\mathrm{H})$, entropy $(\mathrm{S})$ and heat capacity $\left(C_{\mathrm{p}}\right)$ data of more than 17000 chemical compounds (Roine 2010; Kumar et al. 2016).

\subsection{Thermodynamic analysis method}

The equilibrium products at different temperatures and pressures were calculated using the Gibbs free energy minimization method, which has been widely applied for thermodynamic calculations (Adhikari et al. 2007; Nahar and Madhani 2010; López Ortiz et al. 2015). The detailed interpretation of this theory can be referenced by Wang et al. (Wang and Cao 2012; Wang et al. 2014).

The total Gibbs free energy is expressed as Eq. (1). As to chemical reaction equilibrium state, $f_{i}^{\Theta}=p^{\Theta}, f_{i}=y_{i} \varphi_{i} p$, and $\mathrm{G}_{i}^{\Theta}=\Delta \mathrm{G}_{f i}^{\Theta}$ are supposed. With the Lagrange multiplier method, Eqs. (2) and (3) indicate the minimum Gibbs free energy of each gas and total system without solid ones, respectively. Equation (4) is the constraining condition. The vapor-solid phase equilibrium is applied to the Gibbs free energy of carbon, as shown in Eq. (5). Thus, the minimization formation of Gibbs free energy Eq. (6) is obtained by substituting Eq. (1) with Eqs. (3) and (5).

$$
\begin{aligned}
& G^{\mathrm{t}}=\sum_{i=1}^{N} n_{i} G_{i}=\sum_{i=1}^{N} n_{i} \mu_{i}=\sum_{i=1}^{N} n_{i} G_{i}^{\Theta}+\mathrm{R} T \sum_{i=1}^{N} n_{i} \ln \frac{f_{i}}{f_{i}^{\Theta}} \\
& \Delta G_{f i}^{\Theta}+\mathrm{R} T \ln \frac{y_{i} \varphi_{i} p}{p^{\Theta}}+\sum_{k} \lambda_{k} a_{i k}=0 \\
& \sum_{i=1}^{N} n_{i}\left(\Delta G_{f i}^{\Theta}+\mathrm{R} T \ln \frac{y_{i} \varphi_{i} p}{p^{\Theta}}+\sum_{k} \lambda_{k} a_{i k}\right)=0 \\
& \sum n_{i} \alpha_{i k}=A_{k}
\end{aligned}
$$

$$
\begin{aligned}
& G_{\mathrm{C}(\mathrm{g})}=G_{\mathrm{C}(\mathrm{s})} \cong \Delta G_{f \mathrm{C}(\mathrm{s})}=0 \\
& \sum_{i=1}^{N-1} n_{i}\left(\Delta G_{f i}^{\Theta}+\mathrm{R} T \ln \frac{y_{i} \varphi_{i} p}{p^{\Theta}}+\sum_{k} \lambda_{k} \alpha_{i k}\right)+\left(n_{\mathrm{C}} \Delta G_{f \mathrm{C}(\mathrm{s})}^{\Theta}\right)=0
\end{aligned}
$$

In the HSC Chemistry software 6.0, the reaction system needs to be specified, in terms of its phases and species, and the amount of the reactants. The program calculates the amount of products at equilibrium in isothermal or isobaric condition for a heterogeneous system. At the equilibrium state, the free energy of the system is minimized.

It should be noted that these thermodynamic analyses do not include any reaction kinetic limitation or transport process in the real process. However, thermochemical calculations show a great importance in adjusting the feasibility of a reactive process under certain conditions. Here, possible reactions are summarized in Table 1 for the calculations which were carried out based on different types of gases including $\mathrm{CO}, \mathrm{H}_{2}, \mathrm{CO}_{2}$ and $\mathrm{CH}_{4}$, and the solid product of deposition carbon (graphite). Other substances such as alcohols, acids and high hydrocarbons are not taken into account due to their trace contents in the equilibrium

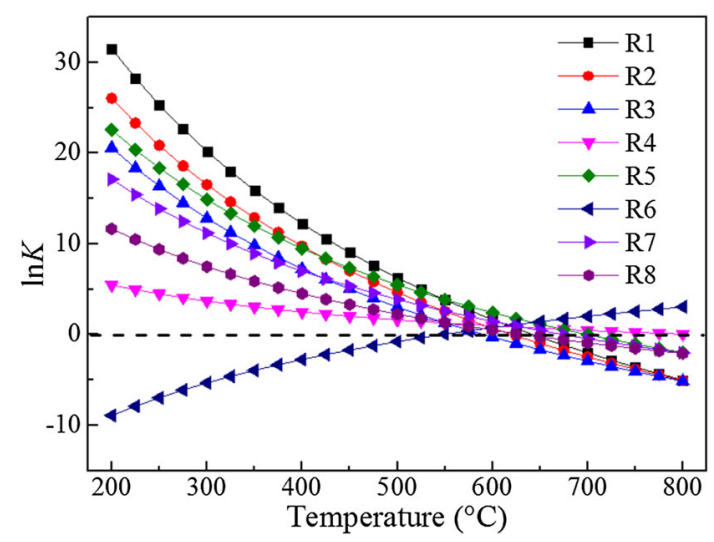

Fig. 1 Equilibrium constants of the reactions as a function of temperature

Table 1 The relevant reactions in the reverse dry reforming reaction

\begin{tabular}{llcl}
\hline Reaction no. & Reaction formula & $\triangle \mathrm{H}_{298 \mathrm{~K}}(\mathrm{~kJ} / \mathrm{mol})$ & Reaction type \\
\hline R1 & $2 \mathrm{CO}+2 \mathrm{H}_{2} \leftrightarrow \mathrm{CH}_{4}+\mathrm{CO}_{2}$ & -247.3 & Reverse dry reforming reaction \\
R2 & $\mathrm{CO}+3 \mathrm{H}_{2} \leftrightarrow \mathrm{CH}_{4}+\mathrm{H}_{2} \mathrm{O}$ & -206.1 & $\mathrm{CO}$ methanation \\
R3 & $\mathrm{CO}_{2}+4 \mathrm{H}_{2} \leftrightarrow \mathrm{CH}_{4}+2 \mathrm{H}_{2} \mathrm{O}$ & -165.0 & $\mathrm{CO}_{2}$ methanation \\
R4 & $\mathrm{CO}+\mathrm{H}_{2} \mathrm{O} \leftrightarrow \mathrm{H}_{2}+\mathrm{CO}_{2}$ & -41.2 & Water-gas shift \\
R5 & $2 \mathrm{CO} \leftrightarrow \mathrm{C}+\mathrm{CO}_{2}$ & -172.4 & Boudouard reaction \\
R6 & $\mathrm{CH} \leftrightarrow 2 \mathrm{H}_{2}+\mathrm{C}$ & +74.8 & Methane cracking \\
R7 & $\mathrm{CO}+\mathrm{H}_{2} \leftrightarrow \mathrm{C}+\mathrm{H}_{2} \mathrm{O}$ & -131.3 & $\mathrm{CO}$ reduction \\
R8 & $\mathrm{CO}_{2}+2 \mathrm{H}_{2} \leftrightarrow \mathrm{C}+2 \mathrm{H}_{2} \mathrm{O}$ & -90.1 & $\mathrm{CO}_{2}$ reduction \\
\hline
\end{tabular}


Fig. 3 Effect of temperature and pressure on catalytic performance. a $\mathrm{CO}$ conversion, b $\mathrm{CH}_{4}$ selectivity, $\mathbf{c} \mathrm{CH}_{4}$ yield, and $\mathbf{d}$ carbon yield

gas mixture. The elemental mass balance is evaluated by carbon, hydrogen, and oxygen.

The conversion of $\mathrm{CO}$, selectivities of $\mathrm{CH}_{4}$ and $\mathrm{CO}_{2}$, yields of $\mathrm{CH}_{4}$ and solid carbon are calculated as follows:

$X_{\mathrm{CO}}(\%)=\frac{F_{\mathrm{CO}, \text { in }}-F_{\mathrm{CO}, \text { out }}}{F_{\mathrm{CO}, \text { in }}} \times 100$

$S_{\mathrm{CH}_{4}}(\%)=\frac{F_{\mathrm{CH}_{4} \text { out }}}{F_{\mathrm{CH}_{4}, \text { out }}+F_{\mathrm{CO}_{2} \text {,out }}+F_{\mathrm{C}, \text { out }}} \times 100$

$S_{\mathrm{CO}_{2}}(\%)=\frac{F_{\mathrm{CO}_{2} \text {, out }}}{F_{\mathrm{CH}_{4} \text {, out }}+F_{\mathrm{CO}_{2} \text {, out }}+F_{\mathrm{C}, \text { out }}} \times 100$

$Y_{\mathrm{CH}_{4}}(\%)=\frac{F_{\mathrm{CH}_{4}, \text { out }}}{\sum_{i} N_{i} F_{i}, \text { in }} \times 100$

$Y_{\text {carbon }}(\%)=\frac{F_{\mathrm{C}, \text { out }}}{\sum_{i} N_{i} F_{i}, \text { in }} \times 100$

Here, $i$ indicates all carbon containing species (CO, $\mathrm{CO}_{2}, \mathrm{CH}_{4}$ and $\left.\mathrm{C}_{2} \mathrm{H}_{4}\right)$ at inlet, and $N_{i}$ indicates the number of carbon atom of $i$-th species.

\subsection{Experimental study}

The alumina $\left(191 \mathrm{~m}^{2} / \mathrm{g}\right.$, Shandong Aluminum Co., China) supported homemade $\mathrm{Ni}$-based catalyst was prepared by the co-impregnation method, as described in Meng's works (Meng et al. 2017). The Ni-based catalyst, with the $\mathrm{Ni}$ loading of $20 \mathrm{wt} \%$ and La loading of $4 \mathrm{wt} \%$, showed the specific surface area of $128 \mathrm{~m}^{2} / \mathrm{g}$ and pore size of $5.1 \mathrm{~nm}$, and the catalyst was denoted as ExCat. To validate the thermodynamic calculations, the RDR reaction was carried out in a stainless steel, high-pressure fixed-bed tube reactor $(10 \mathrm{~mm} \times 2 \mathrm{~mm} \times 500 \mathrm{~mm})$ within the temperature

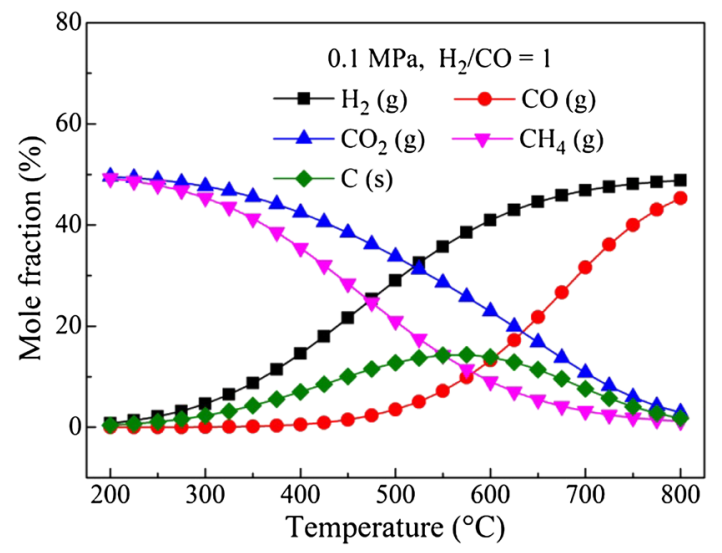

Fig. 2 Equilibrium mole fraction of related substances in RDR reaction
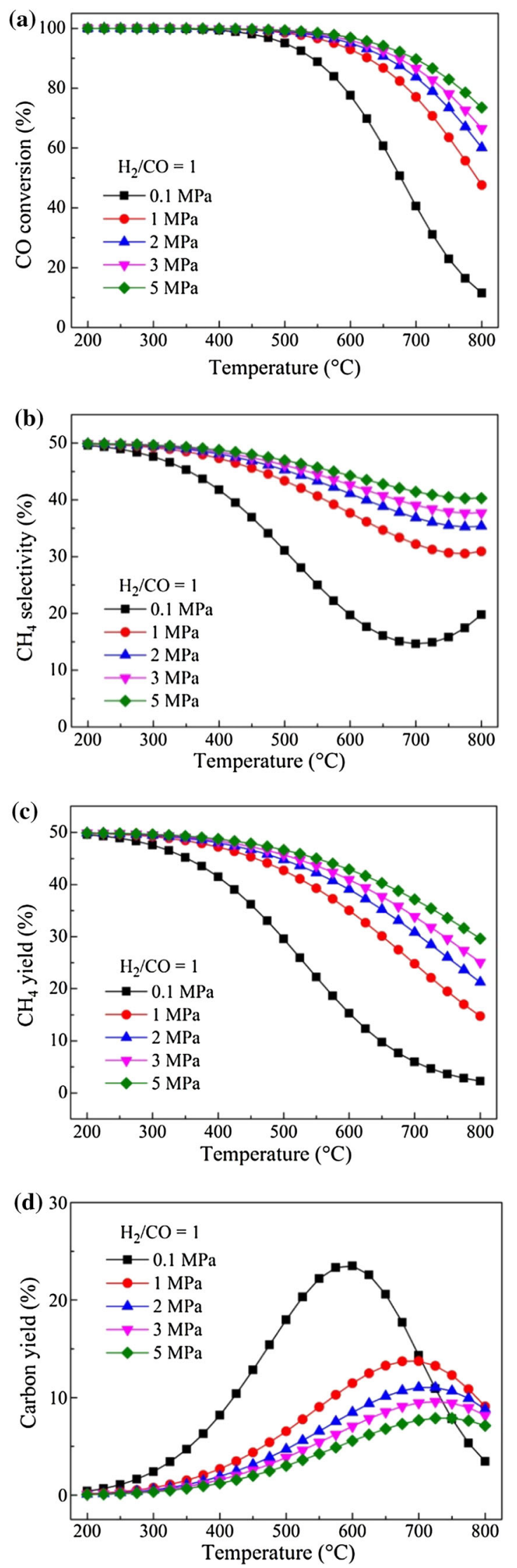
Fig. 4 Effect of $\mathrm{H}_{2} / \mathrm{CO}$ molar ratio on catalytic performance. a $\mathrm{CO}$ conversion, b $\mathrm{CH}_{4}$ selectivity, $\mathbf{c} \mathrm{CH}_{4}$ yield, and $\mathbf{d}$ carbon yield

range of $300-550{ }^{\circ} \mathrm{C} .300 \mathrm{mg}$ of $\mathrm{Ni} / \mathrm{Al}_{2} \mathrm{O}_{3}$ catalyst $(20-40$ mesh) was placed in the reactor. Prior to the RDR reaction, the catalyst was reduced at $550{ }^{\circ} \mathrm{C}$ in a $\mathrm{H}_{2}(99.99 \%$, purchased from Taiyuan Iron \& Steel (Group) Co., Ltd., China) flow diluted with $25 \% \mathrm{~N}_{2}(99.995 \%$, purchased from Taiyuan Iron \& Steel (Group) Co., Ltd., China) for $6 \mathrm{~h}$. A mixed feed gases of $\mathrm{H}_{2} / \mathrm{CO}=1$ (the gas of $\mathrm{CO}$ with a purity of $99.9 \%$ was purchased from Taiyuan Iron \& Steel (Group) Co., Ltd., China) were introduced and controlled with the mass flow controller (MFC), preheat treatment was finished at $200{ }^{\circ} \mathrm{C}$ in first oven at a space velocity of $20000 \mathrm{~mL} /(\mathrm{g} \mathrm{h})^{-1}$. In the second oven, two thermocouples are employed for the reaction. One is placed closely to the reactor, in the middle of the oven to control the oven temperature. The other one is placed inside of the catalyst bed for the measurement of reaction temperature of catalyst bed. The outlet gas steam was cooled by condenser $\left(2{ }^{\circ} \mathrm{C}\right)$ and quantitatively analyzed by an online gas chromatography (GC, Agilent 7890A) using helium (99.999\%, purchased from Taiyuan Iron \& Steel (Group) Co., Ltd., China) as the carrier gas. The GC equipped with a flame ionization detector (FID) with an HP-AL/S column was employed to analyze $\mathrm{CH}_{4}$, and a thermal conductivity detector (TCD) equipped with a Porapak-Q column, HPPLOT/Q column, and HP-MOLESIEVE column was employed to analyze $\mathrm{CO}_{2}, \mathrm{CO}$, and $\mathrm{N}_{2}$.

\section{Results and discussion}

\subsection{Equilibrium analysis of the reactions}

The equilibrium constants $K$ of R1-R8 at various temperatures are shown in Fig. 1. The value of $K$ is calculated using the Van't Hoff equation:

$\frac{\mathrm{d} \ln K^{\Theta}}{\mathrm{d} T}=\frac{\Delta_{r} H_{m}^{\Theta}}{\mathrm{R} T^{2}}$

It can be seen in Fig. 1, as the temperature increases, all the $K$ values decrease except that of R6, which agrees with the Le Chatelier's principle. R1, R2, R3, R5, and R7 play important roles in the RDR reaction system. When the temperature is lower than $500{ }^{\circ} \mathrm{C}$, the equilibrium constant $K$ reduces in the order of $\mathrm{R} 1>\mathrm{R} 2>\mathrm{R} 5>\mathrm{R} 3>\mathrm{R} 7>$ $\mathrm{R} 8>\mathrm{R} 4>\mathrm{R} 6$. Among all these reactions, R1 and R2 show elative high $K$ values at low temperatures, which will lead to the high conversions of $\mathrm{CO} . \mathrm{CO}_{2}$ could be converted via reactions of $\mathrm{R} 3$ and $\mathrm{R} 8$; however, the $\mathrm{CO}_{2}$ cannot be fully converted, which is due to that the reactions
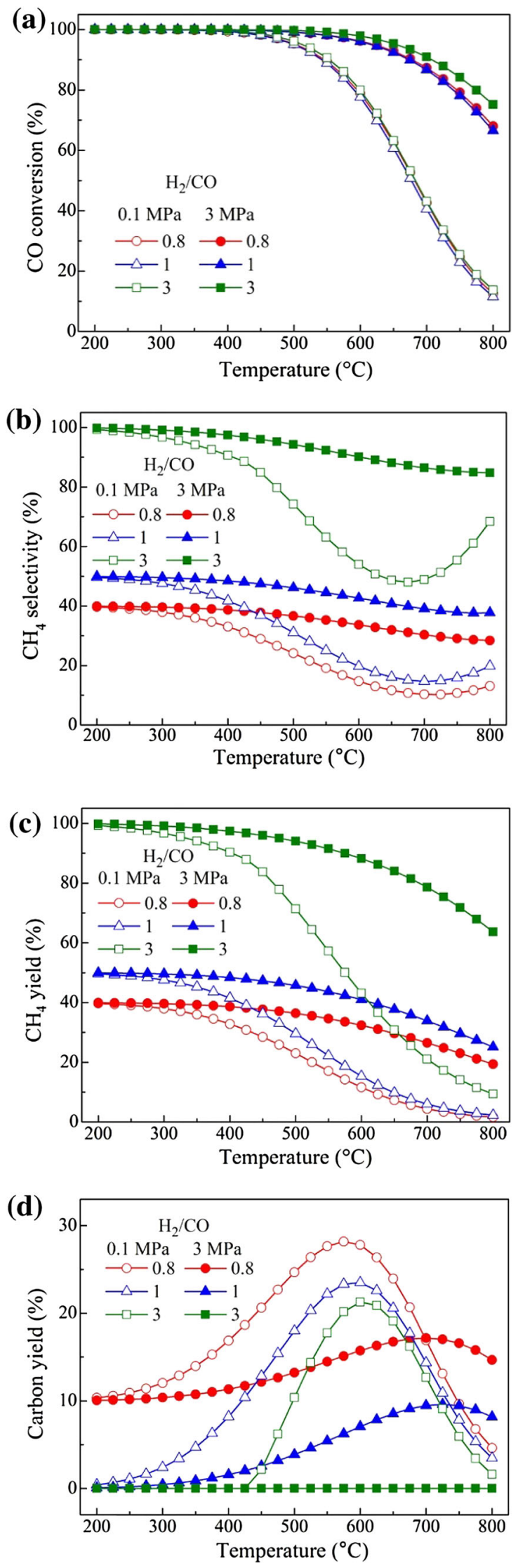
Fig. 5 Effect of $\mathrm{H}_{2} \mathrm{O}$ added in the feed gas on catalytic performance. a $\mathrm{CO}$ conversion, b $\mathrm{CH}_{4}$ selectivity, $\mathbf{c} \mathrm{CO}_{2}$ selectivity, and $\mathbf{d}$ carbon yield

of R1, R4, and R5 generate $\mathrm{CO}_{2}$. Moreover, the solid carbon generated from the reaction of $\mathrm{R} 5$ to $\mathrm{R} 8$, and the Boudouard reaction (R5) acts a dominant role due to its largest $K$ value. Importantly, all these reactions may occur simultaneously in the system, resulting in a balanced composition of the products.

\subsection{Equilibrium compositions}

Figure 2 shows the methanation products with their mole fractions at equilibrium temperatures at $0.1 \mathrm{MPa}$. The feed gas contains $\mathrm{H}_{2}$ and $\mathrm{CO}$ with a $\mathrm{H}_{2} / \mathrm{CO}$ stoichiometric ratio of 1. The products mainly consist of $\mathrm{CH}_{4}$ and $\mathrm{CO}_{2}$ in the temperature range of $200-400{ }^{\circ} \mathrm{C}$. The mole fractions of $\mathrm{CH}_{4}$ and $\mathrm{CO}_{2}$ decrease as the temperature increases, whereas the mole fractions of $\mathrm{H}_{2}$ and $\mathrm{CO}$ exhibit the opposite trend. This can be explained by that the methanegenerating reactions (R1-R3) are exothermic reactions and a higher temperature inhibits them. It is also found that the mole fraction of $\mathrm{CH}_{4}$ is lower than that of $\mathrm{CO}_{2}$. At a low $\mathrm{H}_{2} / \mathrm{CO}$ ratio, the Boudouard reaction (R5) is more preferable, leading to a large amount of $\mathrm{CO}_{2}$ and solid carbon. On the other side, the amount of $\mathrm{H}_{2}$ is higher than that of $\mathrm{CO}$, as shown in Fig. 2. when the temperature over $550{ }^{\circ} \mathrm{C}$, the $\mathrm{CO}$ mole fraction increases linearly with temperature, which is due to the inhibition of the RDR reaction and the $\mathrm{CO}$ produced by the reverse Boudouard reaction (Nahar and Madhani 2010). The solid carbon is produced between 300 and $800{ }^{\circ} \mathrm{C}$, with a maximum amount around $575^{\circ} \mathrm{C}$. Boudouard reaction will not occur when the temperature reaches $700{ }^{\circ} \mathrm{C}$ or higher, as shown in Fig. 1, from which the solid carbon is mainly derived from the methane cracking reaction $\mathrm{R} 6$. Once the solid carbon produced, it may cover the active sites and results in catalyst deactivation (Takenaka et al. 2008). Thus to emphasize, a proper temperature below $600{ }^{\circ} \mathrm{C}$ for RDR reaction is focused, in looking for a high yield of methane.

\subsection{Effect of temperature and pressure}

The effects of temperature and pressure on RDR reaction are shown in Fig. 3. Figure 3a shows that the $\mathrm{CO}$ can be fully converted when the temperature was below $400{ }^{\circ} \mathrm{C}$, further increasing the temperature resulted in the decrease of $\mathrm{CO}$ conversion, from the reason of the exothermic nature of RDR reaction. At a constant temperature, a higher pressure promotes the $\mathrm{CO}$ conversion due to the volume reducing nature of $\mathrm{RDR}$ reaction. The above results
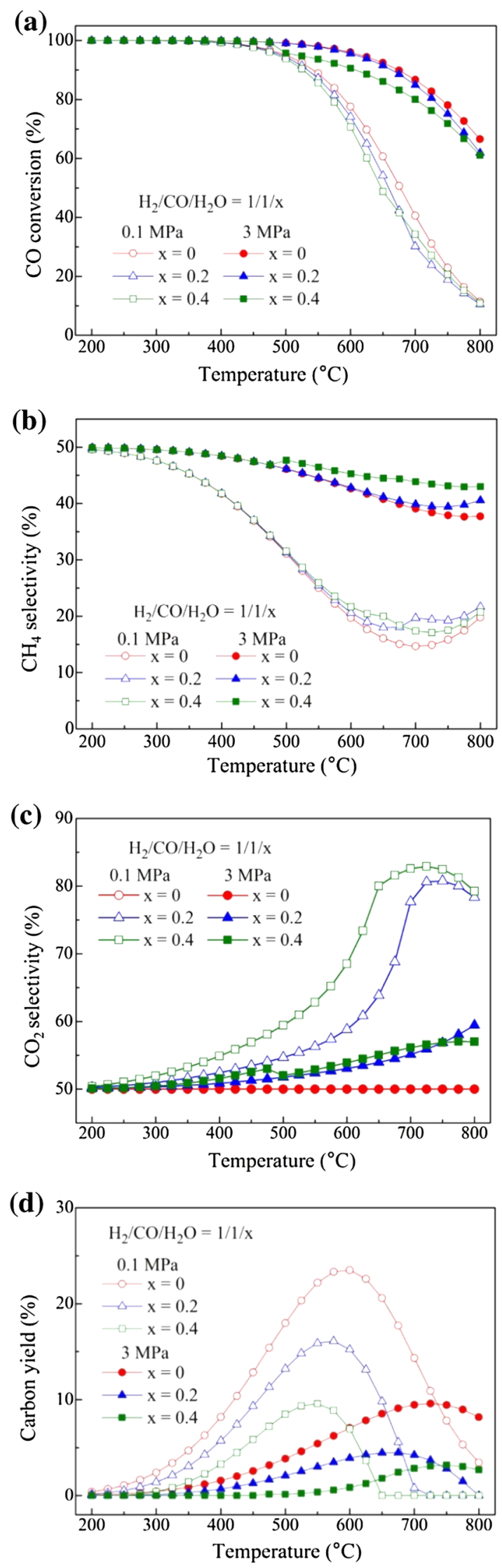
Fig. 6 Effect of $\mathrm{CH}_{4}$ imputed into the feed gas on catalytic performance. a $\mathrm{CO}$ conversion, b $\mathrm{CH}_{4}$ selectivity, $\mathbf{c} \mathrm{CO}_{2}$ selectivity, and $\mathbf{d}$ carbon yield

indicate that a lower temperature and a higher pressure are favorable for the RDR reaction, in terms of increasing $\mathrm{CO}$ conversion. On the other hand, the increasing range of $\mathrm{CO}$ conversion is not obvious when the pressure is higher than $1 \mathrm{MPa}$. In Fig. 3b, high $\mathrm{CH}_{4}$ selectivity is obtained at low temperatures and high pressures. This is because all the methane producing reactions are volume reducing and exothermic. When the temperature is higher than $550{ }^{\circ} \mathrm{C}$, the $K$ value of R5 is comparatively larger than that of R1 (Fig. 1), and the Boudouard reaction (R5) becomes dominantly in the reaction system, leading to a high $\mathrm{CH}_{4}$ selectivity at relative low temperatures. In Fig. $3 c, a \mathrm{CH}_{4}$ yield close to $50 \%$ is obtained in the temperature ranges of 200-300 ${ }^{\circ} \mathrm{C}$ from 1 to $5 \mathrm{MPa}$. Thus, to get a comparatively high $\mathrm{CO}$ conversion and $\mathrm{CH}_{4}$ yield, the conditions of high pressure and low temperature are recommended. Knowing that low temperature is not benefit to accelerate the reaction rate and high pressure is harmful for the equipment, a pressure range of 2-3 MPa and a temperature range of $300-500{ }^{\circ} \mathrm{C}$ are favorable for the RDR reaction.

The variation of carbon yield is presented in Fig. 3d. All these carbon yield curves exhibit a volcano characteristic, with less yield of carbon at high pressures. The solid carbon results from many reactions, including R5, R6, R7, and R8 (as shown in Table 1), from which have different $K$ values. Since the $K$ value of R6 is negative at $200-550{ }^{\circ} \mathrm{C}$ and the value of R5 is higher than that of R7 and $\mathrm{R} 8$ at $200-800{ }^{\circ} \mathrm{C}$ (Fig. 1), so R5 is the main reason for the deposition of carbon. At the point of $0.1 \mathrm{MPa}$ and around $575{ }^{\circ} \mathrm{C}$, the carbon yield reaches the maximum (23\%). Accordingly, at this condition, the occurrence of R6 triggered a higher production of carbon. However, further increase the temperature results in the decrease of carbon yield, possibly because the reverse reactions of R5, R7 and $\mathrm{R} 8$ consumes a comparable amount of solid carbon.

\subsection{Effect of $\mathrm{H}_{2} / \mathrm{CO}$ ratio}

Since the produced gas derived from coal gasification has a varying ratio of $\mathrm{H}_{2} / \mathrm{CO}$ (Zheng and Furinsky 2005), there is a need to investigate the effect of $\mathrm{H}_{2} / \mathrm{CO}$ ratio on performance of RDR reaction. Figure $4 \mathrm{a}$ exhibits the effect of $\mathrm{H}_{2} / \mathrm{CO}$ molar ratio on $\mathrm{CO}$ conversion. The $\mathrm{CO}$ conversion changes slightly as the $\mathrm{H}_{2} / \mathrm{CO}$ ratio increases. When the pressure is $3 \mathrm{MPa}$, the $\mathrm{CO}$ conversion reaches nearly $100 \%$ in the temperature range of $200-550{ }^{\circ} \mathrm{C}$. Figure $4 \mathrm{~b}$ shows the changes of $\mathrm{CH}_{4}$ selectivity. A high $\mathrm{H}_{2} / \mathrm{CO}$ ratio improves the selectivity of $\mathrm{CH}_{4}$, as it can be found when
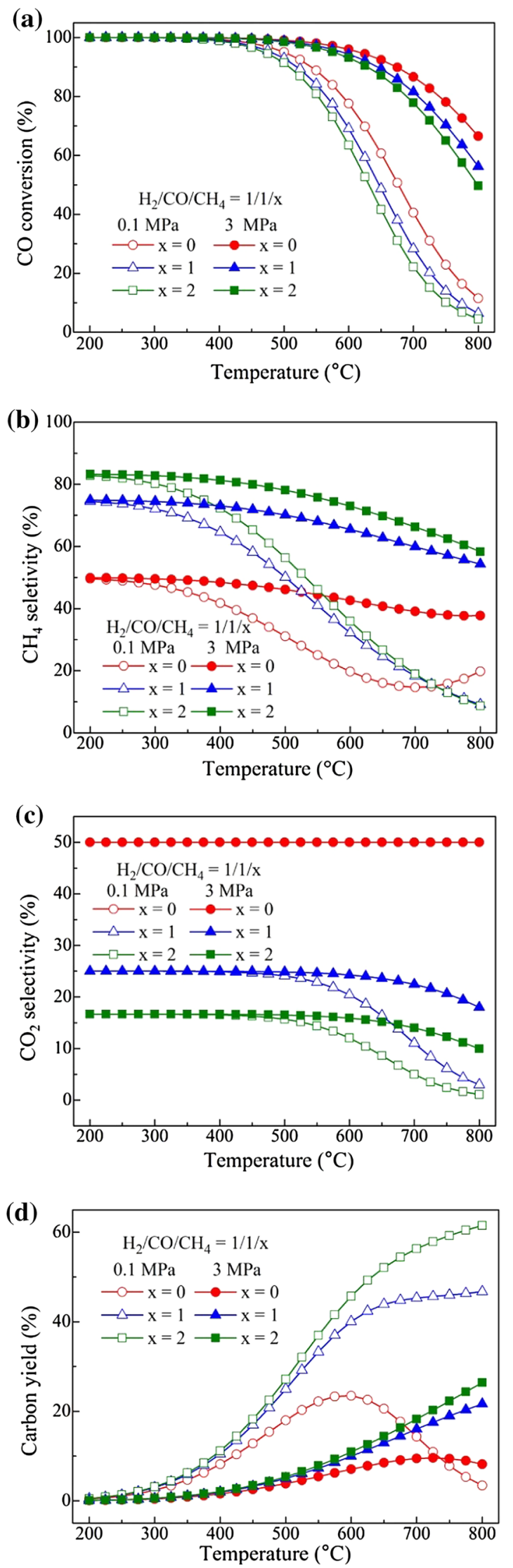
Fig. 7 Effect of $\mathrm{CO}_{2}$ introduced into the feed gas on catalytic performance. a $\mathrm{CO}$ conversion, b $\mathrm{CH}_{4}$ selectivity, $\mathbf{c} \mathrm{CO}_{2}$ selectivity, and $\mathbf{d}$ carbon yield

the $\mathrm{H}_{2} / \mathrm{CO}$ ratio is 0.8 , the maximum $\mathrm{CH}_{4}$ selectivity of $40 \%$ can be obtained. Considering the nearly $100 \% \mathrm{CO}$ conversion below $450{ }^{\circ} \mathrm{C}$, there should be much carbon deposition (see Fig. 4d). When the $\mathrm{H}_{2} / \mathrm{CO}$ ratio increased to 1 , the corresponding initial $\mathrm{CH}_{4}$ selectivity increases to $50 \%$. Further increase $\mathrm{H}_{2} / \mathrm{CO}$ ratio to 3 , the $\mathrm{CH}_{4}$ selectivity enhanced remarkably to $100 \%$. In addition, high pressure is favorable to improve the $\mathrm{CH}_{4}$ selectivity. So a high $\mathrm{H}_{2} / \mathrm{CO}$ ratio or pressure value is useful for SNG production. Figure $4 \mathrm{c}$ reveals the variations of $\mathrm{CH}_{4}$ yield. Higher $\mathrm{H}_{2} / \mathrm{CO}$ ratio or pressure and lower temperature lead to a higher $\mathrm{CH}_{4}$ yield. Figure $4 \mathrm{~d}$ demonstrates the variation of carbon yield. When the $\mathrm{H}_{2} / \mathrm{CO}$ ratio is 0.8 , a significant amount of carbon is produced, because a large amount of unreacted $\mathrm{CO}$ is converted to solid carbon via R5. The highest carbon yield is $28 \mathrm{~mol} \%$ at $0.1 \mathrm{MPa}$. To avoid such carbon deposition, high $\mathrm{H}_{2} / \mathrm{CO}$ ratio and high pressure are recommended for the RDR reaction.

\subsection{Effect of $\mathrm{H}_{2} \mathrm{O}$ content}

Steam controls the $\mathrm{H}_{2} / \mathrm{CO}$ ratio via WGS reaction ( $\left.\mathrm{R} 4\right)$, which is mostly used in methanation and ammonia synthesis industrial process. Moreover, it can be also used for eliminating the carbon deposition to some extent via reverse $\mathrm{R} 7$ and $\mathrm{R} 8$.

The effect of steam content in feed gas is shown in Fig. 5. As can be found in Fig. 5a, the introduction of steam slightly decreases the $\mathrm{CO}$ conversion at 0.1 and $3 \mathrm{MPa}$. Although the steam does not participate in the RDR reaction, it can inhibit the methanation reaction $\mathrm{R} 2$ and thus decrease the $\mathrm{CO}$ conversion. As shown in Fig. 5b, steam has a small effect on the selectivity of $\mathrm{CH}_{4}$. However, the selectivity of $\mathrm{CO}_{2}$ significantly increases as the amount of steam increases at $0.1 \mathrm{MPa}$ (Fig. 5c). From Fig. 5d, the additional steam decreases the yield of carbon, especially at high pressures. When the steam ratio reaches 0.4 at $3 \mathrm{MPa}$, only trace amount of carbon is formed at the temperature higher than $650{ }^{\circ} \mathrm{C}$. This is because the added steam promotes the reverse $\mathrm{R} 8$ reaction. This is also verified by Fig. 5c, where the addition of steam results in the increase of $\mathrm{CO}_{2}$ selectivity. In industrial methanation processes, such as High Combined Shift Methanation (HICOM) (Ensell and Stroud 1983) and Ralph M. Parsons (RMP) (G. A White et al. 1975), certain amount of steam is required to eliminate the solid carbon.
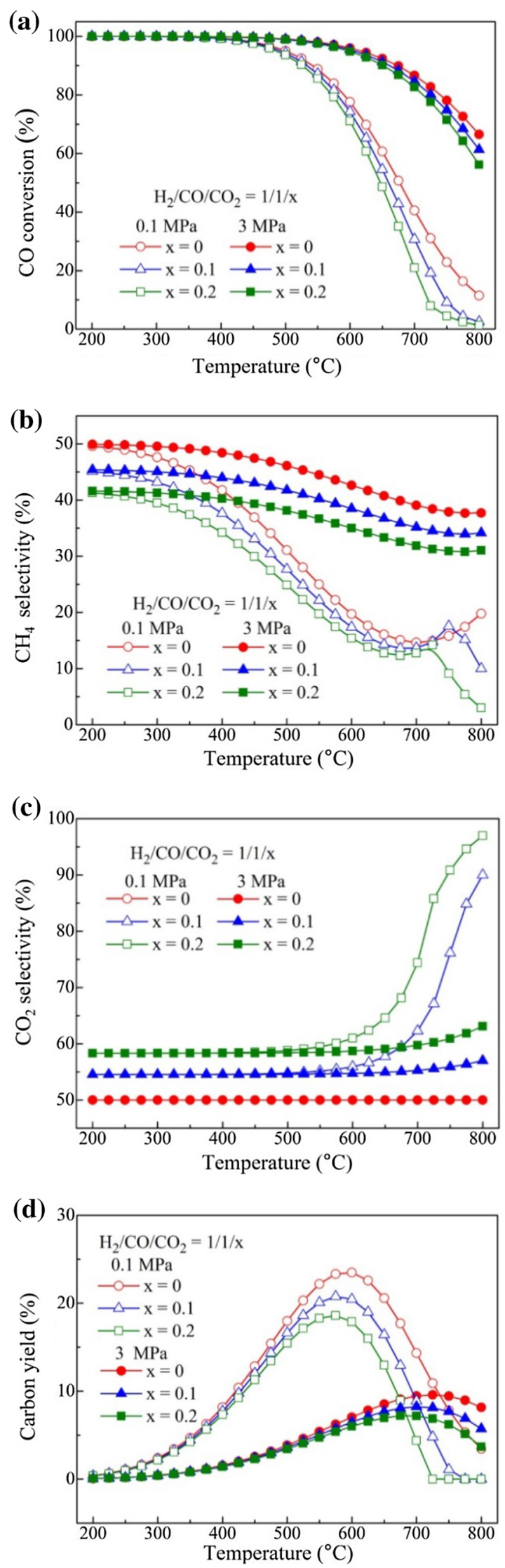
Fig. 8 Effect of $\mathrm{O}_{2}$ imported into the feed gas on catalytic performance. a $\mathrm{CO}$ conversion, b $\mathrm{CH}_{4}$ selectivity, $\mathbf{c} \mathrm{CO}_{2}$ selectivity, and $\mathbf{d}$ carbon yield

\subsection{Effect of $\mathrm{CH}_{4}$ content}

The syngas, derived from gasification of coal, frequently contains a certain amount of $\mathrm{CH}_{4}$. In addition, the contained $\mathrm{CH}_{4}$ in methanation products is generally cycled to dilute the feed gas, in order to avoid reaction temperature run away from the fixed-bed technology (Rönsch et al. 2016). Thus, to study the effect of $\mathrm{CH}_{4}$ on the $\mathrm{RDR}$ reaction is of necessity. Figure 6a shows the effect of $\mathrm{CH}_{4}$ content on $\mathrm{CO}$ conversion. Additional $\mathrm{CH}_{4}$ results in slight decrease of $\mathrm{CO}$ conversion at both 0.1 and $3 \mathrm{MPa}$. The reason is that $\mathrm{CH}_{4}$ is the product of reactions $\mathrm{R} 1, \mathrm{R} 2$ and R3. Introduction of $\mathrm{CH}_{4}$ can inhibit these reactions (R1, R2 and R3), and thus decrease the CO conversion. In Fig. $6 \mathrm{~b}$ and $\mathrm{c}$, additional $\mathrm{CH}_{4}$ greatly improves the $\mathrm{CH}_{4}$ content in the product and reduces the $\mathrm{CO}_{2}$ selectivity at both 0.1 and $3 \mathrm{MPa}$, especially at low temperatures. However, the introduction of $\mathrm{CH}_{4}$ into the feed gas sharply exacerbates the deposition of solid carbon, especially at high temperatures (Fig. 6d). Increasing pressure is very effective to reduce the carbon deposition. Comparing to $0.1 \mathrm{MPa}$, the carbon yield has been greatly reduced at $3 \mathrm{MPa}$. Interestingly, increasing the $\mathrm{CH}_{4}$ ratio from 1 to 2 increases slightly the carbon yield, when the temperature was lower than $600{ }^{\circ} \mathrm{C}$. Therefore, to enhance the $\mathrm{CH}_{4}$ yield and avoid the deposition of carbon, a certain content of $\mathrm{CH}_{4}$ in feed gas or product gas for recycling should not be ignored and the temperature should not exceed $600{ }^{\circ} \mathrm{C}$.

\subsection{Effect of $\mathrm{CO}_{2}$ content}

Usually, the syngas needs to be purified to remove the acidic gas, such as $\mathrm{CO}_{2}$. In this section, the effect of $\mathrm{CO}_{2}$ on the RDR reaction is elucidated. Figure 7 shows the effect of $\mathrm{CO}_{2}$ content on the performance. In Fig. 7a, the increasing of $\mathrm{CO}_{2}$ ratio results in a slightly decrease of $\mathrm{CO}$ conversion, because the addition of $\mathrm{CO}_{2}$ inhibits the RDR reaction and probably accelerates the reaction rate of $\mathrm{CO}_{2}$ methanation (R3), based on the Le Chatelier's principle. Figure $7 \mathrm{~b}, \mathrm{c}$ reveal the effect of $\mathrm{CO}_{2}$ on the selectivities of $\mathrm{CH}_{4}$ and $\mathrm{CO}_{2}$, respectively. As the $\mathrm{CO}_{2}$ amount increases, the selectivity of $\mathrm{CH}_{4}$ decreases gradually at 0.1 and $3 \mathrm{MPa}$. However, the selectivity of $\mathrm{CO}_{2}$ exhibits the opposite trend, especially when the temperature is higher than $600{ }^{\circ} \mathrm{C}$ at $0.1 \mathrm{MPa}$, the selectivity of $\mathrm{CO}_{2}$ increases significantly under the high $\mathrm{CO}_{2}$ amount. Meanwhile, the carbon yield (see Fig. 7d) drops gradually with an increasing of $\mathrm{CO}_{2}$ ratio, due to the inhibition of Boudouard
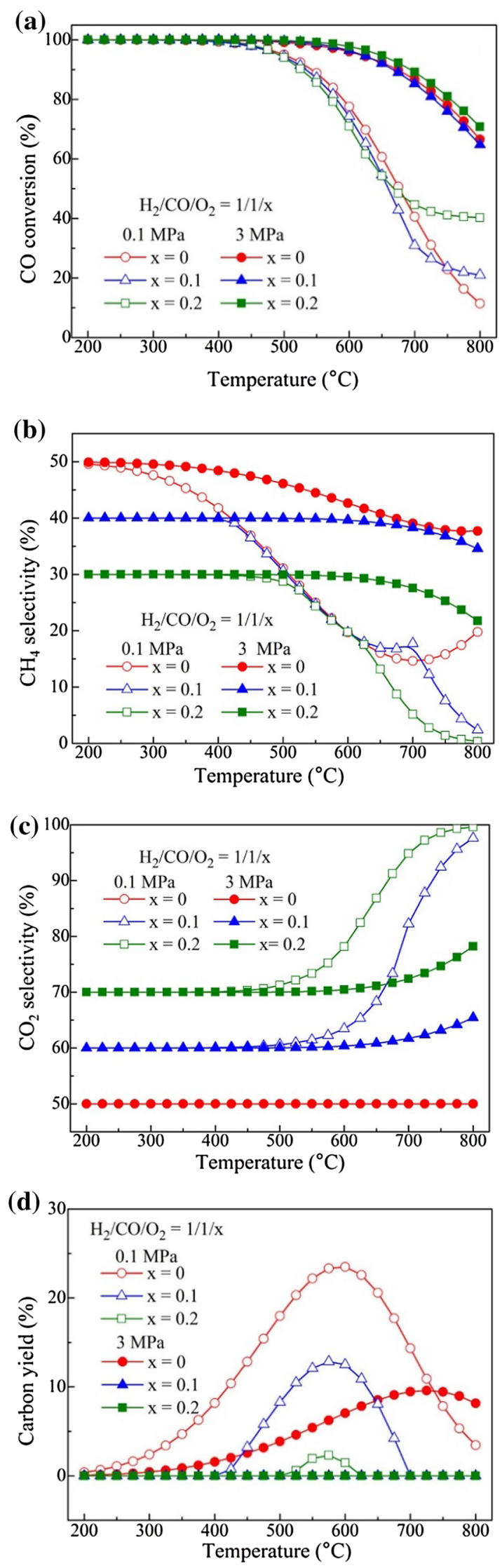
Fig. 9 Effect of $\mathrm{C}_{2} \mathrm{H}_{4}$ brought into the feed gas on catalytic performance. a $\mathrm{CO}$ conversion, b $\mathrm{CH}_{4}$ selectivity, $\mathbf{c} \mathrm{CO}_{2}$ selectivity, and $\mathbf{d}$ carbon yield

reaction (R5). To decrease the carbon yield, the addition of $\mathrm{CO}_{2}$ could work at both pressures. In brief, high pressure inhibits carbon formation, however, it is better to remove the $\mathrm{CO}_{2}$ in the syngas to get a high methane yield.

\subsection{Effect of $\mathrm{O}_{2}$ content}

In addition to steam, air and oxygen are also used as the feed gases for the coal gasification to produce the syngas. Thus, the effect of $\mathrm{O}_{2}$ amount on the RDR reaction is necessary to be studied. The results are shown in Fig. 8. Figure 8a depicts the effect of $\mathrm{O}_{2}$ amount on $\mathrm{CO}$ conversion. The $\mathrm{CO}$ conversion exhibits almost no change at $200-500{ }^{\circ} \mathrm{C}$ at a constant pressure. However, when the temperature is higher than $500{ }^{\circ} \mathrm{C}$, as the $\mathrm{O}_{2}$ amount increases, the $\mathrm{CO}$ conversion decreases slightly at 3.0 MPa. It is probably due to that a small amount of $\mathrm{O}_{2}$ reacts with the $\mathrm{CH}_{4}$ (partial oxidation of methane, $1 / 2 \mathrm{O}_{2}+\mathrm{CH}_{4} \leftrightarrow \mathrm{CO}+2 \mathrm{H}_{2}$ ), which changes the $\mathrm{CO}$ conversion. Figure $8 \mathrm{~b}$ shows the effect of $\mathrm{O}_{2}$ amount on $\mathrm{CH}_{4}$ selectivity. In the range of $200-500{ }^{\circ} \mathrm{C}$, as the $\mathrm{O}_{2}$ content rises, the selectivity of $\mathrm{CH}_{4}$ decreases especially at a high pressure. It is because that, when $\mathrm{O}_{2}$ is introduced into the reaction system, it reacts with $\mathrm{CO}$ to generate $\mathrm{CO}_{2}$, resulting in the decrease of $\mathrm{CH}_{4}$ selectivity. Another reason could be the reaction of partial oxidation of methane that consumes $\mathrm{CH}_{4}$, which also decreases the $\mathrm{CH}_{4}$ selectivity. From Fig. 8c, the $\mathrm{CO}_{2}$ selectivity increases as the $\mathrm{O}_{2}$ content rises, especially when the temperature is higher than $500{ }^{\circ} \mathrm{C}$ at $0.1 \mathrm{MPa}$. It is due to that the $\mathrm{CO}$ and the produced solid carbon are oxygenated by $\mathrm{O}_{2}$, especially at high temperatures. Both of the possibilities result in the increase of $\mathrm{CO}_{2}$ selectivity. In Fig. 8d, the addition of $\mathrm{O}_{2}$ reduces the carbon yield to a large extent at 0.1 and $3 \mathrm{MPa}$, due to the fact that solid carbon reacts with the $\mathrm{O}_{2}$. It is noticeable that no carbon is formed at $3 \mathrm{MPa}$ when the $\mathrm{O}_{2}$ ratio is 0.1 or 0.2 . Therefore, to obtain a high $\mathrm{CH}_{4}$ yield, from the thermodynamic point of view, the feed gas should contain none of $\mathrm{O}_{2}$.

\subsection{Effect of $\mathrm{C}_{2} \mathrm{H}_{4}$ content}

In the process of coal gasification, some trace amounts of high hydrocarbons are produced, such as $\mathrm{C}_{2} \mathrm{H}_{6}$ and $\mathrm{C}_{2} \mathrm{H}_{4}$. Here, $\mathrm{C}_{2} \mathrm{H}_{4}$ is taken as a typical hydrocarbon to study the effect on performance. From Fig. $9 \mathrm{a}, \mathrm{b}, \mathrm{C}_{2} \mathrm{H}_{4}$ slightly affects the $\mathrm{CO}$ conversion and $\mathrm{CH}_{4}$ selectivity. This is mainly due to that, $\mathrm{C}_{2} \mathrm{H}_{4}$ is not involved in the reactions
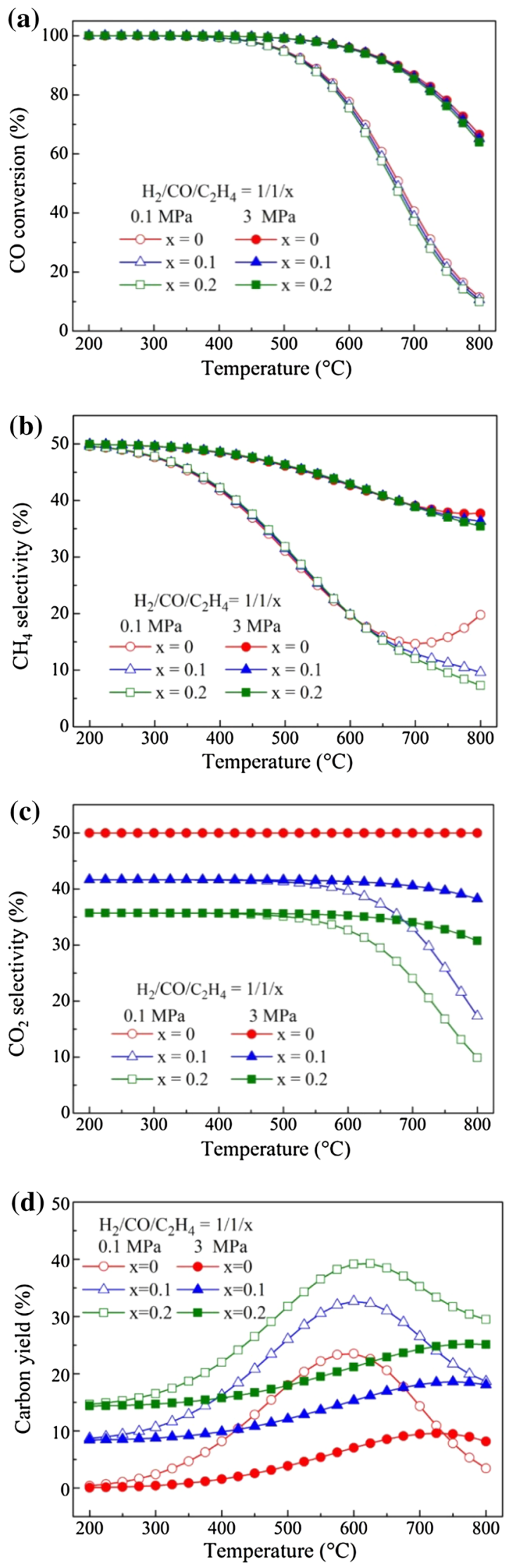
Fig. 10 Comparison between experimental results and calculated ones at various temperatures and pressures. a $\mathrm{CO}$ conversion, $\mathbf{b} \mathrm{CH}_{4}$ selectivity, $\mathbf{c} \mathrm{CO}_{2}$ selectivity, $\mathbf{d}$ Carbon yield

( $\mathrm{R} 1, \mathrm{R} 2, \mathrm{R} 4$ and $\mathrm{R} 5)$, and in which $\mathrm{CO}$ is a reactant. This observation agrees with Gao's results (Gao et al. 2012). However, as shown in Fig. 9c, the $\mathrm{CO}_{2}$ selectivity decreases as the $\mathrm{C}_{2} \mathrm{H}_{4}$ ratios increases. Figure $9 \mathrm{~d}$ shows that the carbon yield rises rapidly with increasing the $\mathrm{C}_{2} \mathrm{H}_{4}$ ratio, especially at $0.1 \mathrm{MPa}$. The temperature corresponding to the maximum carbon yield is around $600{ }^{\circ} \mathrm{C}$. It can be concluded that at low pressure $(0.1 \mathrm{MPa})$ and high temperatures (about $600{ }^{\circ} \mathrm{C}$ ), the reaction of $\mathrm{C}_{2} \mathrm{H}_{4}$ cracking $\left(\mathrm{C}_{2} \mathrm{H}_{4} \leftrightarrow \mathrm{C}+2 \mathrm{H}_{2}\right)$ should not be ignored. Whereas at high pressure ( $3 \mathrm{MPa}$ ), the carbon yield is remarkably reduced. Therefore, as an impurity, the $\mathrm{C}_{2} \mathrm{H}_{4}$ content must be controlled to prevent the formation of solid carbon.

\subsection{Comparison between thermodynamic calculations and experimental results}

The RDR activity test was carried out on ExCat to compare the experimental results with thermodynamic calculations. Both the results at various temperatures and pressures are shown in Fig. 10. Figure 10a shows the comparisons of CO conversion. Thermodynamically, the equilibrium conversion of $\mathrm{CO}$ is almost $100 \%$ between 200 and $400{ }^{\circ} \mathrm{C}$, further increasing the temperature decreases the $\mathrm{CO}$ conversion, especially at a low pressure $(0.1 \mathrm{MPa})$. Experimental results show that the CO conversion firstly increases and then decreases as the temperature rises and the highest $\mathrm{CO}$ conversion was obtained around $400{ }^{\circ} \mathrm{C}$. The high pressure is benefit to improve the $\mathrm{CO}$ conversion. It should be noted that the experimental conversion of $\mathrm{CO}$ at $400{ }^{\circ} \mathrm{C}$ or below is much lower than that of the calculated values, which may be due to the low reaction rate at low temperatures. When the temperature is $400{ }^{\circ} \mathrm{C}$ or higher, the experimental results show good accordance with the calculated ones.

Figure 10b shows the $\mathrm{CH}_{4}$ selectivity at various temperatures and pressures. The calculated results shows that increasing temperature decreases the $\mathrm{CH}_{4}$ selectivity, whereas the increasing pressure enhances the $\mathrm{CH}_{4}$ selectivity. At low temperature and pressure, the experimental results are slightly higher than the calculation ones, while at high temperature, the experimental $\mathrm{CH}_{4}$ selectivity is much higher than the calculated one. Figure 10c shows the comparison of $\mathrm{CO}_{2}$ selectivity. The calculation results exhibit that the selectivity of $\mathrm{CO}_{2}$ is constant at various temperatures and pressures, and the experimental results
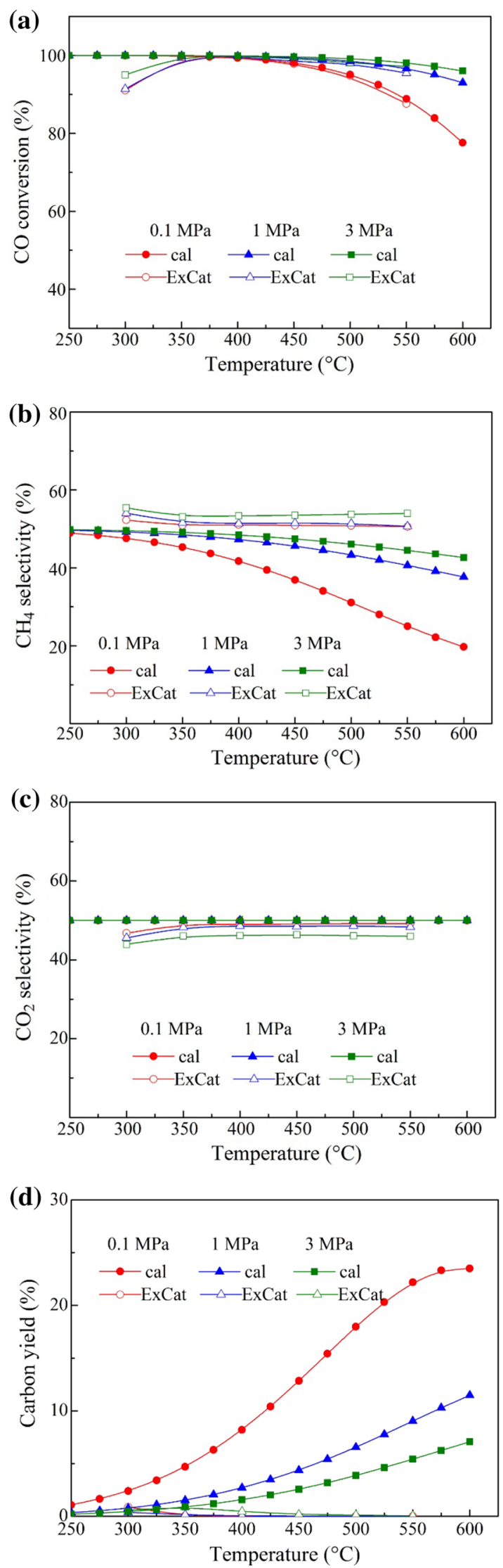
are slightly lower than the calculation ones. The above comparison show that more amount of $\mathrm{CO}_{2}$ converted to $\mathrm{CH}_{4}$ during the reaction. Figure 10d shows the comparison of carbon yields. The calculated carbon yields rose as the temperature increased, and decreased as the pressure increased, which means a large amount of $\mathrm{CO}$ is converted to carbon. However, the experimental results show that the yields of carbon were nearly zero, probably due to the catalyst inhibit the formation of carbon. The above discussion show that the experimental results are generally in accordance with the calculated ones at different temperatures and pressures. The result also indicates that the Gibbs free energy minimization method is an ideal tool for thermodynamic analysis of the RDR process.

\section{Conclusions}

A detailed thermodynamic equilibrium analysis of reverse dry reforming (RDR) reaction by minimizing the Gibbs free energy method in the range of $200-800{ }^{\circ} \mathrm{C}$ and 0.1-3 MPa, and an experimental results in the range of $300-550{ }^{\circ} \mathrm{C}$ and $0.1-3 \mathrm{MPa}$ are studied. The calculation results demonstrate that low temperature and high pressure are beneficial for the $\mathrm{CO}$ conversion and $\mathrm{CH}_{4}$ yield, and high $\mathrm{H}_{2} / \mathrm{CO}$ ratio (at least 1) promotes $\mathrm{CH}_{4}$ yield and decreases carbon yield. In the range of $200-500{ }^{\circ} \mathrm{C}$ and 1-5 MPa, the $\mathrm{CO}$ conversion and $\mathrm{CH}_{4}$ yield reach $95 \%$ $100 \%$ and $43 \%-50 \%$, respectively. Steam in the feed gas enhances the $\mathrm{CO}_{2}$ selectivity and inhibits the generation of carbon, almost no carbon formed at the $\mathrm{H}_{2} / \mathrm{CO} / \mathrm{H}_{2} \mathrm{O}$ ratio of $1 / 1 / 0.4$, when the temperature is below $600{ }^{\circ} \mathrm{C}$ at $3 \mathrm{MPa}$. $\mathrm{CH}_{4}$ contained in the recycling product gas elevates the $\mathrm{CH}_{4}$ content in the products, but also leads to more solid carbon at $500-800{ }^{\circ} \mathrm{C}$, especially at $0.1 \mathrm{MPa}$. $\mathrm{CO}_{2}$ has a negative effect on $\mathrm{CH}_{4}$ selectivity, but it could result in a slightly decrease of carbon yield at the temperature higher than $500{ }^{\circ} \mathrm{C} . \mathrm{O}_{2}$ is not preferable for increasing $\mathrm{CH}_{4}$ selectivity and decreasing the $\mathrm{CO}_{2}$ selectivity although it decreases the carbon yield. $\mathrm{C}_{2} \mathrm{H}_{4}$ is prone to crack, creating a high carbon yield. As impurities, $\mathrm{O}_{2}$ and $\mathrm{C}_{2} \mathrm{H}_{4}$ should be completely removed to get a high $\mathrm{CH}_{4}$ yield. The experimental data are consistent with the calculation ones, indicating that minimizing the Gibbs free energy is effective to analyze the RDR reaction thermodynamically. This work is expected to provide a valuable suggestion in the process optimization for SNG production by combining $\mathrm{CO}$ methanation with WGS reaction.

Acknowledgements This work was supported by Youth Foundation of Shanxi Province (No. 2013021007-4) and National Basic Research Program of China (No. 2012CB723105).
Open Access This article is distributed under the terms of the Creative Commons Attribution 4.0 International License (http://crea tivecommons.org/licenses/by/4.0/), which permits unrestricted use, distribution, and reproduction in any medium, provided you give appropriate credit to the original author(s) and the source, provide a link to the Creative Commons license, and indicate if changes were made.

\section{References}

Adhikari S, Fernando S, Haryanto A (2007) A Comparative Thermodynamic and Experimental Analysis on Hydrogen Production by Steam Reforming of Glycerin. Energy Fuels 21:2306-2310

BP (2016) Statistical Review of World Energy. June

Ensell R, Stroud H (1983) The British gas HICOM methanation process for SNG production. In: Proceedings of the international gas research conference, UK: British Gas Corporation pp 472-481

Gao J, Wang Y, Ping Y, Hu D, Xu G, Gu F, Su F (2012) A thermodynamic analysis of methanation reactions of carbon oxides for the production of synthetic natural gas. RSC Adv 2:2358-2368

Gao J, Liu Q, Gu F, Liu B, Zhong Z, Su F (2015) Recent advances in methanation catalysts for the production of synthetic natural gas. RSC Adv 5:22759-22776

Gao Y, Meng F, Li X, Wen J, Li Z (2016) Factors controlling nanosized $\mathrm{Ni}-\mathrm{Al}_{2} \mathrm{O}_{3}$ catalysts synthesized by solution combustion for slurry-phase $\mathrm{CO}$ methanation: the ratio of reducing valences to oxidizing valences in redox systems. Catal Sci Technol 6:7800-7811

Götz M, Lefebvre J, Mörs F, McDaniel Koch A, Graf F, Bajohr S, Reimert R, Kolb T (2016) Renewable Power-to-Gas: a technological and economic review. Renew Energy 85:1371-1390

Huo J, Yang D, Xia F, Tang H, Zhang W (2013) Feasibility analysis and policy recommendations for the development of the coal based SNG industry in Xinjiang. Energy Policy 61:3-11

Jiang M, Wang B, Lv J, Wang H, Li Z, Ma X, Qin S, Sun Q (2013) Effect of sulfidation temperature on the catalytic activity of $\mathrm{MoO}_{3} / \mathrm{CeO}_{2}-\mathrm{Al}_{2} \mathrm{O}_{3}$ toward sulfur-resistant methanation. Appl Catal A: Gen 466:224-232

Jiang M, Wang B, Yao Y, Wang H, Li Z, Ma X, Qin S, Sun Q (2014) Effect of stepwise sulfidation on a $\mathrm{MoO}_{3} / \mathrm{CeO}_{2}-\mathrm{Al}_{2} \mathrm{O}_{3}$ catalyst for sulfur-resistant methanation. Appl Catal A: Gen 469:89-97

Kopyscinski J, Schildhauer TJ, Biollaz SMA (2010) Production of synthetic natural gas (SNG) from coal and dry biomass-A technology review from 1950 to 2009. Fuel 89:1763-1783

Kumar N, Roy A, Wang Z, L'Abbate EM, Haynes D, Shekhawat D, Spivey JJ (2016) Bi-reforming of methane on Ni-based pyrochlore catalyst. Appl Catal A: Gen 517:211-216

Li H, Yang S, Zhang J, Kraslawski A, Qian Y (2014a) Analysis of rationality of coal-based synthetic natural gas (SNG) production in China. Energy Policy 71:180-188

Li S, Ji X, Zhang X, Gao L, Jin H (2014b) Coal to SNG: technical progress, modeling and system optimization through exergy analysis. Appl Energ 136:98-109

López Ortiz A, Pallares Sámano RB, Meléndez Zaragoza MJ, CollinsMartínez V (2015) Thermodynamic analysis and process simulation for the $\mathrm{H}_{2}$ production by dry reforming of ethanol with $\mathrm{CaCO}_{3}$. Int J Hydrogen Energy 40:17172-17179

Lu B, Ju Y, Kawamoto K (2014) Conversion of producer gas using NiO/SBA-15 obtained with different synthesis methods. Int J Coal Sci Technol 1:315-320 
Martelli E, Kreutz T, Carbo M, Consonni S, Jansen D (2011) Shell coal IGCCS with carbon capture: conventional gas quench vs. innovative configurations. Appl Energ 88:3978-3989

Meng F, Li Z, Ji F, Li M (2015a) Effect of $\mathrm{ZrO}_{2}$ on catalyst structure and catalytic methanation performance over Ni-based catalyst in slurry-bed reactor. Int J Hydrogen Energy 40:8833-8843

Meng F, Li Z, Liu J, Cui X, Zheng H (2015b) Effect of promoter Ce on the structure and catalytic performance of $\mathrm{Ni} / \mathrm{Al}_{2} \mathrm{O}_{3}$ catalyst for $\mathrm{CO}$ methanation in slurry-bed reactor. J Nat Gas Sci Eng 23:250-258

Meng F, Li X, Li M, Cui X, Li Z (2017) Catalytic performance of CO methanation over La-promoted $\mathrm{Ni} / \mathrm{Al}_{2} \mathrm{O}_{3}$ catalyst in a slurry-bed reactor. Chem Eng J 313:1548-1555

Messerle VE, Ustimenko AB, Lavrichshev OA (2016) Comparative study of coal plasma gasification: simulation and experiment. Fuel 164:172-179

Miguel CV, Soria MA, Mendes A, Madeira LM (2015) Direct $\mathrm{CO}_{2}$ hydrogenation to methane or methanol from post-combustion exhaust streams - A thermodynamic study. J Nat Gas Sci Eng 22:1-8

Nahar GA, Madhani SS (2010) Thermodynamics of hydrogen production by the steam reforming of butanol: analysis of inorganic gases and light hydrocarbons. Int J Hydrogen Energy 35:98-109

Roine A (2010) Chemical reaction and equilibrium software with extensive thermo-chemical database. Outokumpu HSC 6.0, Chemistry for Windows

Rönsch S, Schneider J, Matthischke S, Schlüter M, Götz M, Lefebvre J, Prabhakaran P, Bajohr S (2016) Review on methanation From fundamentals to current projects. Fuel 166:276-296

Sahebdelfar S, Takht Ravanchi M (2015) Carbon dioxide utilization for methane production: a thermodynamic analysis. J Petrol Sci Eng 134:14-22
Shen F, Liu J, Zhang Z, Yang Y (2016) Temporal measurements and kinetics of selenium release during coal combustion and gasification in a fluidized bed. J Hazard Mater 310:40-47

Shinde VM, Madras G (2014) CO methanation toward the production of synthetic natural gas over highly active $\mathrm{Ni} / \mathrm{TiO}_{2}$ catalyst. AIChE J 60:1027-1035

Takenaka S, Orita Y, Umebayashi H, Matsune H, Kishida M (2008) High resistance to carbon deposition of silica-coated Ni catalysts in propane stream reforming. Appl Catal A: Gen 351:189-194

Wang W, Cao Y (2012) Combined Carbon Dioxide Reforming with Steam Reforming of Ethanol for Hydrogen Production: thermodynamic Analysis. Int J Green Energy 9:503-516

Wang B, Liu S, Hu Z, Li Z, Ma X (2014) Active phase of highly active $\mathrm{Co}_{3} \mathrm{O}_{4}$ catalyst for synthetic natural gas production. RSC Adv 4:57185-57191

Wang Y, Su Y, Zhu M, Kang L (2015) Mechanism of CO methanation on the $\mathrm{Ni}_{4} / \gamma-\mathrm{Al}_{2} \mathrm{O}_{3}$ and $\mathrm{Ni}_{3} \mathrm{Fe} / \gamma-\mathrm{Al}_{2} \mathrm{O}_{3}$ catalysts: a density functional theory study. Int $\mathrm{J}$ Hydrogen Energy 40:8864-8876

White GA, Roszkowski TR, Stanbridge DW (1975) The RMProcess. Methanation of Synthesis Gas, Advances in Chemistry, American Chemical Society 146:138-148

Yan X, Liu Y, Zhao B, Wang Z, Wang Y, Liu C (2013) Methanation over $\mathrm{Ni} / \mathrm{SiO}_{2}$ : effect of the catalyst preparation methodologies. Int J Hydrogen Energy 38:2283-2291

Yu Z, Wang F (2010) The technology of Coal gasification. Chemical industry Press, Beijing

Zheng L, Furinsky E (2005) Comparison of Shell, Texaco, BGL and KRW gasifiers as part of IGCC plant computer simulations. Energ Conver Manag 46:1767-1779 